\title{
POTENCIALIDADES E LIMITES DA DEMOCRACIA PARA PENSARMOS O BRASIL NO SÉCULO XXI CONTRA O RETORNO DA DITADURA CIVIL-MILITAR ${ }^{1}$
}

Tulio Barbosa ${ }^{2}$

\section{RESUMO}

Propomos um debate para refletirmos os 50 anos da ditadura civil-militar e como esse momento da História do Brasil ainda firma-se como perigo evidente. Para isso realizamos um balanço das condições políticas nesse início do século XXI que passa pelo questionamento das condições reais da democracia brasileira. Destacamos a necessidade de pensarmos a democracia brasileira como crise permanente, para motivarmos a ampliação da participação de todos os cidadãos na construção de decisões coletivas empreendidas nas ações do Estado. O trabalho visa contribuir para o questionamento da democracia brasileira como carente de política, assim, não nos furtamos de refletir as imposições institucionalizadas do que seja política em oposição ao fazer-se político.

Palavras-chave: democracia; política; Estado; cidadania, autoritarismo.

\section{CAPABILITIES AND LIMITATIONS OF DEMOCRACY IN BRAZIL TO THINK THE 21ST CENTURY AGAINST THE RETURN OF DICTATORSHIP CIVIL-MILITARY}

\begin{abstract}
We propose a debate to reflect the 50 years of civil-military dictatorship and how this moment in the history of Brazil remains as evidence of danger. For this a review of the policy conditions was performed at the beginning of XXI century passing by questioning the actual conditions of Brazilian democracy. We emphasize the need to think Brazilian democracy as a permanent crisis to motivate greater participation of all citizens in the construction of collective decisions on the actions of the state. The work aims to contribute to the questioning of Brazilian democracy that is lacking in politics when compared to institutionalized politics.
\end{abstract}

Keywords: democracy; policy; State; citizenship, authoritarianism

1964-2014 - Aos que lutaram pela liberdade e foram livres na luta.

\section{Introdução}

Tornou-se incontestável ser democrata nas sociedades ocidentais após a queda do muro de Berlim, se não compartilharmos da democracia apenas o antônimo político tomará forma e conduzirá as "coisas": a ditadura. Deste modo, a democracia nas sociedades contemporâneas ocidentais é a única possibilidade de equilíbrio entre as diversas forças e poderes que as regem, mas também fora de nós a ingenuidade ou má-fé (no sentido sartreano), pois temos as delimitações e os limites de nossa democracia como constituição do presente. Avançar politicamente, nesses idos do século XXI, significa ampliar a democracia vigente, para isso faz-se necessário refletirmos as condições construídas 
historicamente por diferentes agentes políticos e seus respectivos papéis na edificação de uma democracia que possa ser continuamente ampliada.

A questão central, portanto, precisa ser pensado o que na democracia precisa ser ampliada? Neste sentido, partimos da dicotomia imaginário-real para refletirmos a democracia no Brasil. Para isso compreendemos o real como a condição objetiva dada e circunstanciada à instrumentalização possível num dado processo histórico, ao passo que o imaginário é a condição simbólica de legitimação dessa realidade ao mesmo tempo em que se forja nas condições efetivadas por um imperativo estruturante, porém, frisamos também que o imaginário é construído via derrubadas de mitos, símbolos e representações, em suma, a dicotomia imaginário-real fomenta constantemente a edificação social, política, econômica e cultural, sem a prevalência de um sobre o outro, pois se trata de movimentos dialéticos sem a abdicação de um para a supremacia do outro. $\mathrm{O}$ real e o imaginário existem não como condição dada, mas norteados ou desnorteados pelos diversos movimentos da História.

Pensar a democracia para compreendermos o Brasil nesse século colabora para tecermos o caminho que o país trilha nesse momento da História do Tempo Presente e como esse trilhar apontará as perspectivas voltadas para as potencialidades e os limites da própria democracia. Os limites devem ser entendidos como constantes, como pontos inoperantes para o avanço das questões pertinentes à democracia, deste modo, podemos afirmar que a democracia na sociedade de classes sempre está em crise, ou seja, os limites definem até onde poderemos avançar e sua persuasão deve-se à constituição simbólica, imaginária e atuante na materialidade do cotidiano. A partir de Bourdieu (1989) temos a compreensão da democracia pela necessidade política e essa como condenação quase que absoluta da maioria em benefício da minoria que é organizadora das burocracias e funções próprias às quais delimitam as atuações e ações do primeiro grupo.

$\mathrm{Na}$ democracia a minoria governa sob a égide da representatividade dos coletivos, na ditadura essa minoria torna-se ainda menor e aflige diretamente toda organização coletiva e representativa, pois não existe necessidade de representar qualquer coisa, pois na ditadura nos dizem o que devemos pensar, como devemos agir e nos organizarmos e se realizamos um feito sem autorização da ordem estabelecida estamos condenados às múltiplas violências.

\section{A crise democrática começou a começar no Brasil?}

É possível pensarmos em uma crise democrática hoje? Talvez ainda estejamos comemorando o fim da ditadura brasileira e com júbilos identifiquemos esse momento da História como normalidade democrática. Talvez, estejamos aflitos diante do quadro democrático que vivemos e mais ainda pelos movimentos de extrema direita iniciados no Brasil com grande apelação à ditadura civil-militar iniciada em 1964 e findada em 1985. Esse retorno à ditadura é pensado por algumas pessoas como solução pertinente para o "caos" estabelecido pela democracia brasileira, isto é, esses apoiadores de regimes autoritários compreendem a organização política brasileira como ineficiente por não ter uma direção única, em outras palavras: um ditador. Existem inúmeros movimentos de extrema-direita no Brasil e os mesmos exigem o retorno da ditadura militar, como a petição pública "Abaixo-assinado: Volta do Regime Militar" que até o mês de julho de 2014 obteve 5.650 assinaturas de apoio ao retorno da ditadura no Brasil. Essa petição apresenta argumentos voltados para o universo simbólico religioso num misto de refutação a esquerda e a própria extrema-direita, porém insistem no golpe militar como solução para os problemas brasileiros: "Por Deus! Pela Pátria e pela Família! Volta do Regime Militar 
Já! A nossa petição tem como objetivo acordar os nossos militares, os nossos generais a dar um golpe de estado imediatamente, antes que seja tarde demais!". (PETIÇÃO PÚBLICA, s.d).

Os autores da petição insistem em acordar os generais para que eles organizem e efetivem um golpe militar no Brasil, como se as instituições públicas estivessem afetadas por um complô terrível contra toda sociedade brasileira e propositalmente os defensores do futuro golpe esquecem-se de todos os males de um governo ditador e como o mesmo apresenta soluções que sejam convenientes apenas aos seus próximos. Também de forma intencional não debatem questões pertinentes que compõe efetivamente o quadro atual dos problemas políticos do Brasil, preferem enumerar o "caos" da democracia superado pela "ordem" ditatorial.

Segundo Capelato (1996) as experiências desastrosas no mundo socialista somada às crises econômicas resultaram num reequilíbrio ideológico pela direita. Assim, movimentos de direita alvoroçam essa segunda década do século XXI pelo caminho da tradição ditatorial como a criação de um partido político militar (Partido Militar Brasileiro - PMB) e a refundação da Aliança Renovadora Nacional (Arena), na contramão do PMB e da Arena se tem o movimento de fundação de um partido neoliberal (Partido Novo) o qual exige o estado tachteriano e outros partidos sem posturas políticas mais definidas como o retorno do Partido Social Democrático (PSD) e o ainda embrionário Rede Sustentabilidade.

As questões para refletirmos sobre a crise permanente da democracia brasileira avolumam-se nessa complexidade de caminhos políticos para pensarmos o país. Os movimentos de direita e extrema-direita são tolerados na sociedade brasileira muito mais do que os de esquerda e extrema-esquerda, não no quesito constitucional, mas pela organização simbólica e prática cotidiana efetuada pelos meios de comunicação, pela mídia em geral, por muitas religiões e por representantes do próprio Estado, como afirmou Bourdieu (1989, p. 166): “[...] o mercado da política é, sem dúvida, um dos menos livres que existem.”. A inexistência de liberdade deve-se ao projeto de hegemonização política empreendido sempre pelas classes dominantes, sob os auspícios dos interesses, conforme Bourdieu (1989), dos que dominam os partidos e deles fazem existências para seus objetivos.

Ao realizarmos articulações escalares partindo do domínio do partido para a democracia como ela se encontra podemos ampliar os sujeitos partidários com seus interesses na atuação direta da política nacional nos seus múltiplos aspectos e consequências, assim, a democracia como se encontra no Brasil precisa ser pensada como estado crítico, pois as participações partidárias não emergem como representatividades amplas, coletivas e plurais, mas como representação de um partido e de seus agentes que precisam, segundo Bourdieu (1989), terem garantias de perpetuarem seus poderes, para isso o processo democrático brasileiro é utilizado de forma pretensiosa na constituição de mandatários consagrados às práticas políticas e essas compreendidas como empresas consorciadas aos interesses das classe dominantes nos aspectos econômicos e políticos, os quais são possíveis pela dominação do campo simbólico.

Capelato (1996) evidencia a necessidade de pensarmos o político pela participação efetiva na elaboração do próprio sentido de política, para isso enaltece os movimentos de resistência iniciados a partir da década de 1970 contra a carestia e voltados também para a construção da democracia brasileira. A crise da nossa democracia precisa ser pensada a partir do abandono das participações populares nas decisões nacionais: “[...] Mas a democracia não tem uma lógica interna inscrita na história. Ela representa o elo de ligação de várias temporalidades. Trata-se de um fazer-se, difícil de ser captado.”. (CAPELATO, 1996, p. 163). Esses elementos incidem sobre nossa reflexão quanto à construção da 
democracia pela diversidade de temporalidades as quais precisam ser focadas na urgência das resistências a tudo aquilo que oprime pela ausência de liberdade, de justiça e igualdade. Com esse conjunto de temporalidades a própria Capelato (1996) questiona a mentalidade política do brasileiro, isto é, a partir de Bourdieu (1989) entendemos que os processos históricos da formação política brasileira colaboraram para uma cultura política nacional vinculada à transferência de nossas responsabilidades políticas para nossas representações partidárias e, desse modo, transferimos para o profissional da política todo nosso poder político. Essa cultura política tem reflexos graves na apelação dos sujeitos pró-ditadura militar, pois os mesmos não desejam pensar ou agir coletivamente, mas, sobretudo, delegar suas competências para outros e isso se torna tão mais alienante para os sujeitos, já que os mesmos não almejam nenhum debate nem mesmo pelo viés partidário.

Neste sentido, a democracia brasileira precisa ser compreendida como em construção, logo a crise instaurada é da própria representatividade partidária e acima de tudo política, pois o fazer-se político na realidade atual brasileira é delegado para as competências partidárias. $\mathrm{O}$ aperfeiçoamento da democracia apenas será possível com a ampliação da participação do povo brasileiro nas suas mais diversas exigências e necessidades, com o alargamento do debate político extrapartidário e também partidário.

A representatividade política, portanto, está em crise na democracia brasileira e essa afirmação pode ser constatada nas inúmeras greves ocorridas no ano de 2014 as quais foram independentes da decisão da direção dos seus respectivos sindicatos dentre tais: os garis no Rio de Janeiro, os motoristas de ônibus em Criciúma e São Paulo (capital) e os professores municipais de Goiânia. Também é preciso destacar as manifestações por todo país em 2013 nas quais a principal palavra de ordem era: "Sem partidos".

Lechner (2004) associa as transformações do mercado aos novos sentidos da política, nessa direção apontamos as transformações neoliberais no final do século passado como contraponto as práticas maximizantes do Estado, pois o Estado mínimo na política econômica neoliberal trouxe uma nova cultura política para o Brasil, já que o mesmo teve, desde então, na iniciativa privada o controle do espaço nacional. A representatividade política, seja partidária ou não, foi impactada pela postura neoliberal de organização do Estado, uma vez que anteriormente o Estado máximo teve atribuições de ditador e o Estado mínimo passa a ser associado à democracia, portanto, ser democrata, nessa visão ideologizada, passa pela anulação do Estado e na prevalência das empresas privadas. Sabemos que esse discurso é operativo para a estruturação das redes de comando das empresas multinacionais no país, em outras palavras, apoiados em Marini (2011), trata-se de uma dependência consentida e ao associarmos com Lechner (2004) podemos interpretar essa crise da representatividade como recuo proposital do Estado para as forças do mercado.

O Estado passa a não ser mais compreendido como instituição de todos, mas como componente num jogo de forças o qual conduz a política para o bem-estar dos seus próximos. Segundo Lechner (2004, p. 16):

Quando a condução política se restringe ao manejo da contingência, incapaz de balizar o futuro possível, o devir se torna imprevisível. À falta de previsão soma-se o desvanecimento de toda e qualquer noção de um amanhã melhor que dê sentido aos sacrifícios atuais. A política assim amesquinhada gera angústia, pois transfere toda a incerteza para o indivíduo. Sozinho, sem ponto de referência nem rede de segurança, ele há de tomar as decisões e assumir os riscos. Já não pode distinguir desejos e temores no tempo; a realidade se impõe, no seu imediatismo, qual um magma infinito. Oprimido, o cidadão acaba por abominar ou 
depreciar a política - suposta instância de proteção e condução - que o traiu.

A traição da política para com o cidadão acaba por ser entendida como a traição de si mesmo, por sua incapacidade de reagir diante das falhas consideradas pelo sujeito necessárias para serem corrigidas, logo o sujeito empreende no outro as suas esperanças e as possibilidades dele avançar numa discussão mais ampla são anulados pela sua delegação de competências própria e necessária para o cidadão. Esse cenário avoluma não o desinteresse pela política, mas o discurso preconceituoso sobre a mesma como salientou Arendt (1999). Não se trata de desinteresse e sim de autoavaliação do sujeito como ser apolítico, o que o leva a sua ineficiente atuação social e por isso prefere delegar todo seu poder político. Deste modo, as ditaduras são instauradas na negação das competências críticas próprias de uma sociedade democrática e forja o autoritarismo no processo de autopreconceito relacionado à autoanulação política. Essa constatação leva-nos hoje a questionarmos a estrutura política brasileira e como a mesma pode armar situações que favoreçam apoio de parte da população às situações antidemocráticas. Paira ainda na sociedade brasileira a construção de um discurso ideologizado que prega os benefícios dos governos militares no Brasil iniciado em 1964, com isso reforça mais ainda a anulação do sujeito na sociedade democrática, deste modo, podemos afirmar que esse discurso anula o papel do sujeito pela formação de uma áurea de glória do passado recente da História brasileira, como afirmou Arendt (1999, p. 30): “[...] O perigo do preconceito reside no fato de originalmente estar sempre ancorado no passo $\{\log \}$ [...] torna impossível uma experiência verdadeira do presente $[\ldots]$ ".

O tempo presente do/no Brasil é democrático e precisa ser pensado a partir do que se tem hoje, da maneira como os nossos cotidianos são social, política, econômica e culturalmente organizados. Neste sentido, não podemos nos furtar do questionamento da construção política empreendida não em espaços de amplos diálogos, mas na disseminação de valores e sentimentos que repulsam tais espaços. A ojeriza da elite econômica e política a qualquer ato público de cunho político é propagada pela mídia em geral e até a comoção de todo país nos protestos realizados em 2013 várias emissoras de televisão e jornais impressos ou digitais propagaram preconceitos quanto às manifestações, como não foi possível interrompe-las pelo apelo midiático tiveram uma solução: apoiaram manifestantes antipartidos e criminalizaram os manifestantes que se identificavam partidariamente ou mesmo representantes de movimentos sociais organizados. Nas manifestações ocorridas na cidade de Uberlândia (MG), nas quais participamos e em vários momentos presenciamos manifestantes vaiaram outros manifestantes pelo simples fato dos mesmos levarem bandeiras de partidos (de esquerda) e até mesmo bandeiras do Movimento Sem-Terra, do Movimento dos Sem-Teto e outras com reivindicações políticas.

A fomentação da raiva para com a política desses manifestantes deve-se, em boa medida, a constituição preconceituosa estabelecida pela classe dominante pelos meios de comunicação e até mesmo pela escola subsumida à lógica do capitalismo neoliberal ambos propagam valores e sentimentos individualistas. A exacerbação do individualismo, segundo Haroche (2008), impede o sujeito de ir além de si mesmo, ou melhor, efetua-se socialmente de forma isolada e tudo que foge de seu "controle" estabelece que não possa ser positivo para si e para os outros. O sujeito isolado passa a ser a medida do mundo, ao contrário da política que necessita do diálogo e do debate constante quando numa sociedade democrática. Debate que precisa ser realizado publicamente com o qual se expõem as ideias e os sujeitos e, desta forma, estabelece a necessidade do notório e esse somente é possível pela construção de espaços cada vez mais públicos. 
Sennett (1999) evidencia o projeto de anulação da espacialidade construída coletivamente e esses espaços tornam-se públicos apenas para a mobilidade enquanto deslocamento funcional no sítio urbano, logo a movimentação leva a anulação dos espaços públicos políticos. Assim, ao costurarmos Bauman (1998) e Haroche (2008) compreendemos o sentido do espaço público político como projeto socialmente anulado, por causa da edificação de uma cultura que necessita do previsível e do controlável e com isso privilegia o isolamento, já que a coletividade sempre leva a impresibilidade. Sennett (1999) enfatiza que não se trata de isolamento físico, pois em muitos escritórios privilegiou-se o fim das paredes e as mesas muito próximas, podemos ainda acrescentar as redes sociais pela internet, porém o isolamento precisa ser compreendido como político, como ineficiente no debate sobre a realidade cotidiano em que vivemos. Haroche (2008) sublinha, a partir de Janet, "[...] o sentimento como condição de engajamento [...] (p. 206), consequentemente pensar a coletividade não a partir de si, mas do mundo (ARENDT, 1999), deste modo, precisa o sujeito sentir pelo outro, incomodar-se e considerar-se parte de uma coletividade.

O espaço público político é no Brasil desconsiderado pelo próprio Estado, já que quando manifestações ocorrem todo aparato repressivo do Estado é enviado e são realizadas inúmeras prisões, violências físicas e verbais contra os manifestantes. Além da mídia ter promovido a classificação dos manifestantes, isto é, como não foi possível criminalizar a classe média que foi as ruas em 2013, a mídia construiu um discurso classificatório no qual existiam manifestantes ordeiros, bons e pacíficos de um lado e do outro os bandidos, criminosos, baderneiros os quais não reivindicavam nada, apenas desejam promover a desordem. Essa classificação veio seguida de outras conclusões realizadas pela própria mídia, dentre tais que as manifestações foram diminuindo em número por causa dos manifestantes violentos, mas jamais foi mencionada a violência do Estado brasileiro repressor.

"Ambos, técnicas sociais de controle e violência, encarregam-se de produzir a figuração da incompetência política da população, especialmente quando esta se organiza, se movimenta, aparece autonomamente.” (PAOLI, 2007, p. 224). Essa aparição autônoma somente é possível com a ampliação do debate referente a política e como a mesma pode contribuir para refletirmos as condições de nossas existências cotidianas. Freiar as ações de lutas e resistências pró-democracia é tarefa permanente das classes dominantes operacionalizadas pelo Estado, mesmo o Estado afirmando constitucionalmente seu caráter democrático. O desafio encontra-se justamente em promover um Estado brasileiro democrático na sua Constituição Federal, enquanto teoria do Estado de Direito, e na prática efetiva do dia a dia.

Essa democracia que inibe as manifestações públicas quando vinculadas a projetos políticos é citada por Parga (2004) como democracias que são mantidas a força e essa força, continua o autor, deve-se a ditadura do econômico sobre o político; assim, o político não pode ser manifestado a menos que concorde plenamente com os projetos econômicos das grandes multinacionais e transnacionais, logo o Estado promovido pela razão econômica propicia a soberania do mercado e com isso impõe "[...] políticas gubernamentales anti-democráticas por parte de gobiernos democráticos [...]" (PARGA, 2004, p. 45).

Não podemos nos furtar do debate político das questões econômicas e pensarmos a democracia brasileira com seus vínculos de dependência ao mercado internacional e as imposições forçosas das empresas ao papel político do Estado brasileiro e como o mesmo precisa se "comportar" diante de alguns temas que possam motivar o descrédito ao status quo estabelecido. Ao mesmo tempo em que as pessoas motivam-se pelos problemas, 
também se desviam de pensá-los como práticas e ações políticas desdobradas nos aspectos econômicos e culturais constituídos dialeticamente. Desviam, pois não buscam consolidar o diálogo e debate de forma que possam consolidar uma perspectiva cada vez mais crítica para a apuração da nossa democracia, isso ocorre pelo papel histórico do sujeito hoje, pela dogmatização das condições de vida pela mídia a serviço da classe dominante e o Estado repressivo em ações violentas ou aparentemente inocentes como a educação.

Diante disso, Fitoussi e Rosanvallon (2003) frisam a individualização e a fragmentação do sujeito como ser vulnerável num mundo caótico, todavia preferimos entender que a caoticidade é proposital e propositiva para os sujeitos não se identificarem com temas comuns que os levem às reivindicações operacionalizadas em espaços públicos e, portanto, construa uma conjunto de experiências que levem os sujeitos a repensarem até mesmo suas práticas domésticas e familiares construindo "[...] la irrupción de la democracia en el corazón de la família [...]” (FITOUSSI \& ROSANVALLON, 2003, p. 49). Portanto, o fortalecimento da democracia brasileira depende, sobretudo, da insistência na verificação dos problemas impeditivos para ampliá-la e nesse sentido passa pelo questionamento, inevitável, do Estado brasileiro e como o mesmo sucumbe diante de projetos econômicos na sociedade de classes.

\section{Pela democracia plena na plena democracia}

São 50 anos desde 1964 e isso causa comoção em todos que pensam uma sociedade livre para o Brasil. A relação ditadura e democracia é nossa História, sucessões de golpes e ditadores perambularam pela História brasileira desde o golpe republicano de 1889. Não é fácil pensarmos a democracia brasileira a partir dos inúmeros abusos produzidos historicamente contra a mesma, mas também não é impossível pensarmos no fortalecimento democrático.

Nossa democracia carece de política. Não a política institucionalizada delimitadora de ações e projetos que vão além dessa institucionalização. Também entendemos que a política é feita pelos movimentos sociais, pelas greves, pelas reivindicações coletivas e resistências contra compra o capitalismo de forma geral, isto é, essas ações políticas são realizadas cotidianamente em todo país. Afirmamos a carência política na nossa democracia como projeto das classes dominantes nacionais e internacionais veiculados ao modo de produção e reprodução capitalista (MARINI, 2011; PARGA, 2004). A carência de política fundamenta-se na inoperatividade do Estado para garantir as manifestações de todos os brasileiros, ou seja, a representatividade política partidária não pode ser a única forma de legitimação dos processos democráticos, existe a necessidade de constituir novos espaços públicos para o aperfeiçoamento da democracia e esses não podem ser delimitados pelo Estado, mas construídos continuamente pelos cidadãos.

A carência política brasileira centra-se na pouca oposição que existe ao Estado autoritário, ou seja, a política não é efetivada de forma constante, mas circunstanciada aliada às necessidades das classes dominantes. Esse papel central do Estado nas escolhas políticas, no rumo da própria concepção de política tem origem no autoritarismo próprio dos sucessivos golpes civis e militares que ocorreram em toda História republicana do Brasil. Baquero (2001, p. 100) interpreta esse cenário da seguinte forma:

[...] pode-se dizer que a experiência política brasileira tem se caracterizado pela predominância de formas autoritárias de governo, gerando, como consequiência, uma restrição às possibilidades de uma participação política mais efetiva. O impacto do autoritarismo, ao longo das últimas décadas, não permitiu que se desenvolvesse um cenário no 
qual a ingerência da sociedade civil no Estado fosse significativa.

Diante disso, reafirmamos a necessidade de ampliarmos o debate quanto aos rumos de nossos cotidianos, quanto aos sentidos de nossa existência na humanidade que constituímos a partir de nosso país. O autoritarismo continua ainda ativo na cultura política brasileira e esse mesmo edifica preconceitos quanto às competências e incompetências dos cidadãos brasileiros referentes às suas decisões políticas. Antecede as decisões na democracia plena debates exaustivos e diálogos carregados de objetivos para a construção de um país melhor, de fato, para todos. Desde a década de 1990 o país mergulhou nas reformas necessárias para a consolidação do capitalismo de mercado e financeiro, as reformas foram substanciais quanto ao papel do Estado para a classe trabalhadora a qual sentiu na lida diária da vida o desemprego, o arrocho salarial, a inflação, aumentos dos juros e a organização do Estado não pelo diálogo com os trabalhadores, mas quase que exclusivo para com os empresários nacionais, internacionais e os latifundiários.

Essas transições quanto ao papel político do Estado em relação aos trabalhadores pelo viés neoliberal atuaram como forças políticas que moldaram o econômico, mas somente foi possível esse modelagem pela domínio dos meios de produção e, lógico, pelo amplo domínio da riqueza circulante. Neste sentido, Harvey (2010, p. 47) entendeu que:

As forças políticas que se uniram na mobilização por trás dessas transições tinham um caráter de classe distinto e vestiram-se com as roupas de uma ideologia distinta chamada neoliberal. A ideologia repousava sobre a ideia de que os mercados livres, o livre comércio, a iniciativa pessoal e o empreendedorismo eram os melhores fiadores da liberdade individual e da liberdade como um todo e que o "Estado-babá" deve ser destruído para o benefício de todos. Mas a prática implicava na ideia de que o Estado estivesse por trás da integridade das instituições financeiras, introduzindo assim (começando pela crise da dívida mexicana e dos países em desenvolvimento de 1982) o "risco moral" de maneira acentuada no sistema financeiro.

A preservação da integridade das instituições financeiras atrela aos trabalhadores a pecha da economia e torna-os cada vez mais distantes das questões políticas levando-os a refletirem sobre suas condições de sobrevivência num mundo avultado pela produção, consumo e circulação. A partir de Parga (2004) compreendemos que a ditadura econômica faz-se atuante nos países periféricos, como o Brasil, e impedem, pela própria ação do Estado, de efetivarem canais mais amplos os quais possibilitem o questionamento amplo de tudo que aí está. As elites, segundo Fitoussi e Rosanvallon (2003,, p. 65), não questionam a situação da classe trabalhadora, por viverem outra realidade:

[...] el imaginário político asimila a las elites a la categoria de quienes no han comprendido el peso de las dificultades cotidianas de la población porque no las viven. Al lado de um "pueblo" que vive en el presente, las elites viven fuera del tiempo. No conocen el desempleo y no sufren [...]

A carência de política na democracia brasileira faz-se no que poderíamos chamar de política do chão de fábrica, de política do sem-terra, dos sem-teto, dos marginalizados, dos excluídos, das ruas, dos trabalhadores, dos desempregados, dos doentes, enfim, a carência de política na sociedade brasileira, mesmo tendo inúmeros movimentos de resistências ao autoritarismo institucionalizado, precisa ser dinamizada no cotidiano e não retirada de uma 
representação política hoje em crise.

As questões levantadas Gomes (1996) quanto a consolidação da representação partidária surgem-nos hoje como distanciamento de qualquer discussão coletiva e pública, pois nesses tempos apolíticos o que menos esperamos do nossos próximos é o debate político quanto as situações vividas cotidianamente. Acreditamos que somos livres e não sofremos nenhuma pressão autoritária, pois o autoritarismo é tido, de forma mentirosa, como inexistente. Vivemos um momento de falsa liberdade, como atestou Bauman (2000, p. 174): "[...] essa liberdade sem precedentes chega num momento em que há pouca utilidade para ela e pouca chance de transformar a liberdade de restrições em liberdade para agir". Bauman (2000) nesse mesmo trabalho inscreve a ação como necessidade política, como sistematização de práticas de resistências anunciadas justamente por meio dessa liberdade programada pelos ditames do capitalismo.

A ditadura civil-militar foi instaurada no Brasil sob a égide do medo, foram organizadas marchas em todo país com amplo apoio da sociedade civil, de setores econômicos, da grande mídia e de inúmeros políticos eleitos democraticamente. $\mathrm{O}$ medo não foi da elite nacional, mas foi essa mesma classe dominante que propagou o terror para a população em geral, terror que seria produzido com o projeto comunista via presidente João Goulart e em pouco tempo a direita se organizou para fundamentar seus argumentos pela fé e a "Marcha da Família com Deus pela Liberdade" justificou toda lógica necessária para o levante dos militares comandados também pela sociedade civil representada pelos grandes industriais, comerciantes e latifundiários, todos esses atrelados aos interesses do capitalismo estadunidense.

50 anos depois de 1964 o terror é a chave mestra na construção de preconceitos, na edificação de valores os quais assustam os moradores do campo e da cidade, um novo terror paira sobre os cidadãos brasileiros: o medo da política. Os discursos anunciados desde 2013 com as manifestações em todo país trazem alguns preocupações para pensarmos a representatividade política, pois a mesma consolida-se junto a preconceitos os quais enumeram os políticos como corruptos e são assim menosprezados, isso significa que a política é mantida na esfera da institucionalidade e foge, por meio da ação dos próprios cidadãos, dos próprios cidadãos. Se o comunismo assustava a família brasileira em 1964, o caos, aparente caos em 2014, desestimulam os brasileiros a pensarem a agir coletivamente, pois agir dessa forma é uma ato político e os mesmos consolidaram opiniões que a política é desnecessária e faz-se apenas na esfera da obrigatoriedade do Estado, da imposição da institucionalização do autoritarismo.

Poderíamos dizer que cada grupo histórico tem uma ideia concreta da sua própria existência, que representa a forma finita de sua escolha de existência; nesse sentido, cada grupo histórico tem um ethos, uma singularidade ética, que é um poder de criação ligado a uma tradição, a uma memória, a um enraizamento arcaico. (RICOUER, 1995, p. 152).

Ao apoiarmos em Ricouer (1995) e Arendt (1999) devemos olhar para o futuro, sem abandonar as expectativas do presente, sem abdicarmos de construirmos os caminhos para garantir o domínio do agora, como também sinalizou Bourdieu (1989) apoiado em Weber, devemos garantir o pleno domínio do presente, sem esse domínio não conseguiremos avançar para ampliarmos uma sociedade mais democrática. Esse domínio do agora, do presente, precisa ser pensado, em linhas gerais, como o domínio do possível, como construção de um projeto mais amplo que possa efetivar a crítica fundamentada ao Estado e seu aparato repressivo e a solução para todos os cidadãos na efetivação de uma democracia ampla e plena. Tal democracia somente ocorrerá pelos caminhos que permitam 
não apenas o domínio das temporalidades, mas sobretudo, das espacialidades, em outras palavras, não se trata apenas de parar o trânsito e impedir o fluxo de automóveis, pois eles param hoje e passam amanhã, trata-se de construir coletivamente espaços nas ruas, nos parques, nas fábricas, no campo, nas escolas, nas universidades, nas igrejas, nos salões de festas, nos terreiros de umbanda e em todos locais pensados.

O avanço da ditadura civil-militar continua, não podemos acreditar no seu fim, pois enquanto existir lutadores para derrubar as tiranias e promover a democracia, também existirão ditadores, sejam reais ou embrionários, para destruir a democracia e a classe trabalhadora. A lição de 1964 é que ela pode se repetir, mas para que isso não ocorra é necessário a plenitude da democracia numa plena democracia possível pela atuação política - no sentido amplo - dos cidadãos brasileiros.

\section{Referências}

ARENDT, H. O que é política? Rio de Janeiro: Bertrand Brasil, 1999.

BAQUERO, MARCELLO. Cultura política participativa e desconsolidação democrática: reflexões sobre o Brasil contemporâneo. São Paulo em Perspectiva, 2001, vol.15, n.4, pp. 98-104.

BAUMAN, Z. Em busca da política. Rio de Janeiro: Zahar, 2000.

BAUMAN, Z. O mal-estar da pós-modernidade. Rio de Janeiro: Zahar, 1998.

BOURDIEU, P. O poder simbólico. Rio de Janeiro: Bertrand/Difel, 1989.

CAPELATO, M. H. R. . Historia Política. Revista de Estudos Históricos, Rio de Janeiro: FGV, v. 9, n. n.17, p. 161-165, 1996.

FITOUSSI, J.P, ROSANVALLON, P. La nueva era de las desigualdades. Buenos Aires: Manantial, 2003.

GOMES, A. C. Política: história, ciência, cultura, etc. Revista de Estudos Históricos, Rio de Janeiro: FGV, v. 9, n. n.17, p. 59-84, 1996.

HAROCHE, C. A condição sensível. Rio de Janeiro: Contra Capa, 2008.

HARVEY, D. Organizando para a transição anticapitalista. Revista Vírus, maio de 2010, p. 35-47.

LECHNER, N. Os novos perfis da política: um esboço. Revista Lua Nova. São Paulo, n. 55, p. 05-20, 2002.

MARINI, R. M. Dialética da dependência. In: TRASPADINI, R., STEDILE, J. P. (orgs.). Ruy Mauro Marini - Vida e obra (textos selecionados). São Paulo: Expressão Popular, 2011.

PARGA, J. S. Por qué se deslegitima la democracia? El desorden democrático. Revista Ecuador Debate. Quito: CAAP, p. 41-82,2004.

PETIÇÃO PÚBLICA. “Abaixo-assinado: Volta do Regime Militar”. Disponível em: http://www.peticaopublica.com.br/pview.aspx?pi=P2011N14172. Acessado em $105 / 07 / 2014$.

PAOLI, M. C. O mundo do indistinto: sobre gestão, violência e política. In: OLIVEIRA, F., RIZEK, C. S. (org.). A era da indeterminação. São Paulo: Boimtepo, 2007. 
RICOUER, P. Em torno do político. São Paulo: Loyola, 1995.

SENNETT, R. O declínio do homem público: as tiranias da intimidade. São Paulo: Companhia das Letras, 1999.

\section{Notas}

${ }^{1}$ Texto resultado das discussões realizadas no evento "50 Anos do Golpe. 30 anos de redemocratização? Um debate interdisciplinar" ocorrido nos dias 08 e 09 de maio na Universidade Federal de Uberlândia (UFU) Campus Santa Mônica. Também o texto tem contribuições de discussões realizadas no âmbito da PósGraduação em História dessa mesma universidade.

${ }^{2}$ Professor do Instituto de Geografia da Universidade Federal de Uberlândia (UFU). Licenciado, mestre e doutor em Geografia pela UNESP. Doutorando pelo Programa de Pós-Graduação em História da UFU. Contato: tulio@ig.ufu.br

Recebido em Janeiro/2014

Aprovado em Fevereiro/ 2014 